\title{
estudos semíóticos
}

\section{Performance musical enquanto objeto de pesquisa*}

\section{Caio Victor de Oliveira Lemos **}

\begin{abstract}
Resumo: Dado o caráter por demais restrito do que se entende por performance nos estudos musicais, este artigo propõe discutir as condições e os meios necessários para a integração dos elementos discursivos pertinentes para que a performance musical, com enfoque na música de concerto ocidental, possa reivindicar autonomia enquanto objeto de pesquisa. Para tanto, tomaremos os pressupostos da semiótica discursiva, incorporando discussões sobre intertextualidade e polifonia. Num primeiro momento, partiremos de um movimento de expansão, no qual se integram elementos intertextuais e contextuais à investigação. Em seguida, ao reconhecer o caráter discursivo/textual desses elementos, discutiremos sua composição sincrética. Isso nos levará à relação enunciador-enunciatário como eixo fundador em torno do qual se organizam os elementos performáticos pertinentes, criando assim um critério ao mesmo tempo constante, porém suficientemente aberto para abarcar as movências do ato performático enquanto objeto de estudo.
\end{abstract}

Palavras-chave: performance musical; sincretismo; intertextualidade.

\footnotetext{
* DOI: https://doi.org/10.11606/issn.1980-4016.esse.2021.186418.

** Docente do curso de Música da Universidade Estadual do Ceará (UECE), campus de Fortaleza, CE, Brasil. Doutorando do Programa de Pós-Graduação em Música do Instituto de Artes da Universidade Estadual Paulista (UNESP), campus de São Paulo, SP, Brasil. E-mail: caiovictordeoliveira@gmail.com. ORCID: https://orcid.org/0000-0002-1103-9627.
} 


\section{Introdução}

A

pesar do processo gradual de estabelecimento da pesquisa em performance musical no meio acadêmico e da constante busca de instrumental e ferramentas teórico-metodológicas que contemplem as problemáticas e subsidiem as investigações, a ênfase na pesquisa em performance é ainda majoritariamente dada à partitura, ao preparo técnico e às informações musicológicas. Instâncias de grande importância e que incidem diretamente na realização musical, mas que constituem apenas parte do ato performático. Em outras palavras, o ato performático não é tratado em sua totalidade, isto é, enquanto texto sincrético que une música, gestualidade e demais elementos sonoros e visuais, que, ao nosso ver, constituem intrinsecamente o objeto e são determinantes para o seu entendimento.

Uma hipótese para a perpetuação dessas balizas na pesquisa pode residir no privilégio frequentemente atribuído aos aspectos teóricos baseados em noções de repetitividade e rigidez aplicados à performance musical, que, por sua vez, deve ser concebida, mais acertadamente, como um objeto em perene movimento, com constante diálogo entre seus participantes. Nesse sentido, ao desconsiderar os aspectos moventes presentes numa realização musical, são perdidos elementos fundamentais para a investigação de seu sentido. Ao tratar de um objeto multiforme e dinâmico, como é o caso da realização musical, nasce a necessidade de traçar novos limites metodológicos e epistemológicos que contemplem sua natureza movente, os valores investidos, bem como as relações sincrônicas e diacrônicas que se estabelecem. Em poucas palavras, é tempo que o performer imprima o seu próprio ponto de vista ao ato performático, delineando assim com clareza a natureza desse objeto de pesquisa.

Em vista disso, e de modo a marcar nossa posição em relação ao objeto, bem como traçar seus limites, pautaremos nossa discussão pelos seguintes pontos: (i) intertextualidade; (ii) texto/contexto; (iii) sincretismo; e (iv) algumas contribuições semióticas para a delimitação do objeto. Esse percurso nos levará às condições necessárias para a delimitação de um objeto de investigação que é necessariamente maior do que o som musical e a partitura, porém suficientemente delimitado para que se diferencie daquilo que de fato podemos considerar externo ao fenômeno.

\section{Intertextualidade}

A performance musical não é um ato descolado de seu contexto sociocultural e está em conexão com toda a tradição que a precedeu. Se, por um lado, é um ato único e irrepetível, assim como todos os atos enunciativos, por outro, é moldada pelo diálogo que estabelece com enunciações anteriores, presentes e mesmo futuras. Todavia, esses diálogos/tensões entre enunciados 
podem ocorrer de diversas maneiras e também em níveis diferentes. Tomaremos como ponto de partida o dialogismo bakhtiniano, já que se trata de um conceito, historicamente, na raiz da noção de intertextualidade (Discini, 2004).

Para Bakhtin, todo enunciado é dialógico, isto é, todo enunciado é heterogeneamente constituído, logo, inevitavelmente atravessado pelo discurso alheio. Dessa maneira, o enunciado não é uma construção exclusivamente individual, mas também coletiva. Individual porque o sujeito mobiliza o esquema linguístico de forma particular; coletiva porque suas escolhas dialogam responsivamente com outros enunciados anteriores, presentes e mesmo futuros.

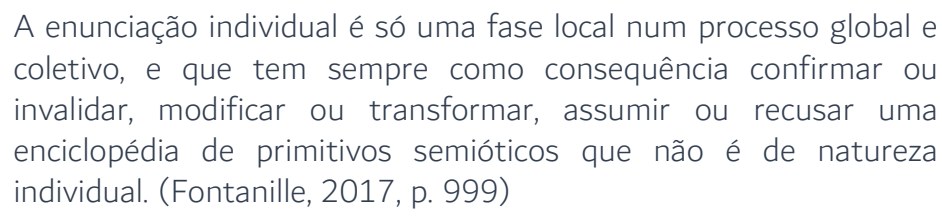

Isso significa que o enunciado possui em si uma latência responsiva, e esses diálogos se marcarão de diversas maneiras no enunciado, como visto na citação acima. O enunciado pode dialogar de forma ampla com a tradição na qual está inserido. Esse é o caso de quando situamos o compositor da obra numa performance musical. Nesse caso, o compositor não é apenas uma indicação causal. Como explica Foucault, "o autor é o que permite explicar tão bem a presença de certos acontecimentos numa obra como suas transformações, suas deformações, suas diversas modificações"1 (Foucault, 2013, p. 282). Dessa forma, "A função autor é, portanto, característica do modo de existência, de circulação e de funcionamento de certos discursos no interior de uma sociedade" (2013, p. 278).

Por outro lado, esse diálogo pode se estabelecer de forma mais clara e específica, como com a citação de um tema ou um motivo musical numa obra, por exemplo. Esses diálogos entre textos não precisam necessariamente se dar a partir de planos de expressões equivalentes, ou seja, um texto que parte de diferente suporte material pode também estabelecer esse diálogo. Um caso comum na área musical é a utilização de títulos na obra de homônimos literários como contos populares, romances, textos filosóficos etc.

A intertextualidade, segundo Discini (2004), é então um tipo específico de diálogo entre enunciados. Tendo por premissa que todo enunciado é heterogeneamente constituído, Authier nos ajuda a delinear a discussão ao separar o discurso/enunciado em marcado ou não marcado, como vemos pela citação a seguir:

\footnotetext{
${ }^{1}$ Poderíamos utilizar o argumento também para a atividade do performer, isto é, sua função autor. Ver Lemos (2018).
} 
Eu distingo neste conjunto (de heterogeneidade mostrada) as formas marcadas, que chamam a atenção sobre o lugar do outro por uma marca unívoca (discurso direto, aspas, itálico, incisos explicativos) e as formas não-marcadas do mostrado, em que o outro se deixa reconhecer sem marcação unívoca (discurso indireto livre, ironia, pastiche, imitação...). (Authier apud Discini, 2004, p. 12)

Discini classifica a intertextualidade como o segundo tipo, ou seja, enquanto heterogeneidade mostrada e não-marcada. No primeiro caso, temos a distinção entre o eu e o outro no enunciado, isto é, o eu dá lugar de fala ao outro enfatizando sua presença. Como exemplificou a autora, abrem-se as aspas, utiliza-se o itálico etc., criando espaço no enunciado para a fala do outro. No segundo caso, sabe-se da presença do outro, mas ele não é demarcado, não há separação entre o eu e o outro. Como explica Discini (2004, p. 11), "na intertextualidade não há fronteiras, não há linha divisória entre o eu e o outro, não há ruptura. Intertextualidade é a retomada consciente, intencional da palavra do outro, mostrada, mas não demarcada no discurso da variante".

Como visto até aqui, toda relação intertextual comporta uma heterogeneidade constitutiva mostrada e não marcada no discurso. Entretanto, não é menos verdade que outras relações dialógicas, como a heterogeneidade não mostrada, também se dão entre textos. Afinal, como mostra Schwartzmann (2018, p. 3), "não há nada que, para a semiótica, não seja texto. Tudo é texto. Não se pode levar a cabo uma análise sem que se tome uma dada grandeza semiótica como um texto". Ainda assim, tomar o conceito de intertextualidade como debatido até aqui, stricto sensu, nos ajudará a entender os níveis de pertinência das grandezas e diferentes tipos de relações envolvidas na análise de nosso objeto.

A relação intertextual pode mostrar-se de diversas maneiras, bem como são plurais os efeitos de sentido fruto desse encontro com o texto-base. A relação pode se mostrar num motivo musical literal ou transfigurado, na utilização de um tema conhecido como mote para a composição de variações, na transfiguração estética de um tema, no arranjo de uma canção etc. Na própria performance $\mathrm{o}$ intérprete pode se remeter a alguma outra performance incorporando elementos interpretativos ou mesmo visuais, de maneira mais ou menos explícita. Se pensarmos num continuum entre presenças mais explícitas e presenças mais veladas, tem-se à disposição uma infinidade de possibilidades. Com isso, são incontáveis também os efeitos de sentido resultantes na construção dessa relação, tais como: sátira, exaltação, crítica, louvor, ironia, sugestão imagética etc. 


\section{Texto e contexto}

Além das relações intertextuais, como as descritas acima, ou seja, a heterogeneidade constitutiva mostrada e não marcada no discurso, podemos aproveitar a separação proposta por Authier para discutir também o outro lado da heterogeneidade constitutiva, a saber, a não mostrada. Nesse caso, pode-se pensar em outras instâncias presentes no ato performático que, todavia, não estabelecem relação clara e específica com um enunciado de base, como vimos para a intertextualidade, mas também deixam rastros no enunciado musical, tais como a situação, o ambiente, a sociedade, a cultura etc., além de relações dialógicas com um grupo de enunciados que perfazem um determinado estilo composicional, uma organização formal semelhante (forma sonata, tema com variações etc.) e assim por diante. Esses elementos são geralmente tratados pelo termo contexto, muitas vezes acrescido de um adjetivo caracterizador (contexto cultural, contexto histórico, contexto social etc.). Trata-se então da relação do enunciado musical não exclusivamente com outros enunciados, mas com instâncias sobre as quais se constrói.

Dada a variedade e a relevância desses elementos não mostrados para a construção de sentidos na performance musical, cabe ao analista traçar os níveis de pertinência dos elementos à disposição e relacioná-los à problemática de sua investigação. Essa seleção é tão mais importante dado o número potencialmente incontável de fatores que podem, em maior ou menor grau, ser relacionados e influenciar a realização musical.

Retomamos a separação sugerida por Authier, sobre a heterogeneidade constitutiva do discurso, com a finalidade de distinguir diferentes tipos de relações dialógicas. Assim, no tópico anterior usamos o conceito de intertextualidade, conforme proposta de Discini, para nos referir à heterogeneidade mostrada e não marcada. Todavia, como já apontamos, ao considerar esses elementos circundantes também como textos, podemos entender as próprias relações contextuais igualmente como relações entre textos. Dessa forma, se aproveitamos a distinção sugerida por Discini, podemos pensar a heterogeneidade mostrada e não marcada como uma relação intertextual stricto sensu e as relações contextuais como relações intertextuais lato sensu. Do ponto de vista metodológico, Barros explica que:

Pode-se caminhar nessa direção e executar a análise contextual, desde que o contexto seja entendido e examinado como uma organização de textos que dialogam com o texto em questão. Assim concebido, o contexto não se confunde com o "mundo das coisas", mas se explica como um texto maior, no interior de que cada texto se integra e cobra sentido. (Barros, 2005, p. 78) 
Dentro desse amplo âmbito do termo contexto, pode-se pensar em esferas mais facilmente relacionáveis ao ato performático e outras de natureza mais velada. Exemplifiquemos. Elementos característicos do ambiente da realização musical podem, por exemplo, justificar escolhas sonoras e/ou gestuais do performer. Como bem sublinha Baz Kershaw, "um princípio fundamental da teoria da performance... é o de que nenhum aspecto do ambiente da performance pode ser descartado como irrelevante perante seu impacto" (Kershaw apud Cook, 2006, p. 18). Dessa forma, a opção de um performer por tocar num registro dinâmico muito alto pode ser marca de um ambiente muito barulhento, isto é, para que o performer se faça escutar é necessário o aumento da amplitude dinâmica. Nesse caso, essa marca no enunciado (dinâmica) apresenta-se de maneira bastante clara.

Por outro lado, poderíamos nos estender para esferas além do ambiente físico da performance, que, no entanto, são condições sine qua non à sua própria realização, como a sociedade, a cultura, o momento histórico, entre outros. Assim, certas escolhas interpretativas (agógica, articulações, andamentos etc.) podem ser fruto de relações menos aparentes e nem sempre deliberadas pelo performer, como a reprodução de valores tidos como eufóricos por uma dada comunidade de ouvintes/espectadores ou por coerções sociais.

Desse modo, percebe-se a falta de alcance que uma investigação na área de performance musical terá ao desconsiderar esses elementos circundantes (aqui chamados de maneira ampla de contexto) ou mesmo incorrer em equívocos. Como explica Barros (2005, p. 78), "O exame interno do texto não é suficiente, no entanto, para determinar os valores que o discurso veicula. Para tanto, é preciso inserir o texto no contexto de uma ou mais formações ideológicas que lhe atribuem, no fim das contas, o sentido". No exemplo que demos sobre a amplitude dinâmica utilizada por um performer, se considerássemos apenas o registro da realização musical retirando-Ihe os elementos da situação e/ou do ambiente, no caso de uma análise descritiva dessa performance, poderíamos chegar à conclusão de que há uma falta de nuances dinâmicas e, consequentemente, atribuir ao performer imperícia na mobilização desse elemento.

Poderíamos estender essas observações para outros parâmetros contextuais da realização musical que se refletirão diretamente nas tomadas de decisão do performer e moldarão suas estratégias discursivas, antes e durante o próprio ato, como aponta Navickaitè-Martinelli (2019, p. 3): "mesmo quando lidamos com questões contextuais, extra- ou para-musicais em torno da performance musical, muito também depende e/ou requer uma quantidade significativa de criatividade por parte do performer". ${ }^{2}$

\footnotetext{
2 Tradução nossa do original: "Even when dealing with contextual, extra- or para-musical matters surrounding the art of musical performance, much also depends on and/or requires a generous amount of creativity on the performer's side".
} 
Dessa maneira, a despeito do trabalho interpretativo e preparatório anterior à performance musical, durante o próprio ato performático o performer deverá se moldar constantemente frente às mais variadas demandas situacionais. Como mostra Patrick Dahlet, ao descrever a relação entre locutor e interlocutor, aqui entendidos como performer e audiência, "todo locutor deve incluir em seu projeto de ação uma previsão possível de seu interlocutor e adaptar constantemente seus meios às reações percebidas do outro" (Dahlet, 2005, p. 57). Em outras palavras, as tomadas de decisão e estratégias discursivas não se restringem apenas à atividade anterior à performance, mas apresentam-se também durante o ato performático, dirigindo assim parte dos percursos de sentido que vão se construindo.

O exemplo dado sobre a mobilização dinâmica, apesar de ilustrado de forma breve e superficial, mostra a pertinência em considerarem-se elementos contextuais, não como acessórios à pesquisa em performance, mas como elementos integrantes do próprio objeto de estudo. Nesse caso, o elemento contextual permite explicar certas presenças e a ausência de elementos na performance musical, bem como as maneiras como são mobilizados os mais diversos parâmetros inerentes à realização musical. Assim, considerado como elemento integrante do nosso objeto de estudo, ele servirá não só ao interesse de uma análise descritiva, como ilustrado acima, mas também poderá explicar ou dar suporte a variadas problemáticas pertinentes à área, seja na preparação para a performance, na elaboração interpretativa, nas estratégias discursivas utilizadas, na construção da imagem do intérprete enquanto enunciador etc.

Ingrid Monson faz observação semelhante ao considerar os textos musicais não apenas como produtos do contexto, mas também como formadores do próprio contexto:

\begin{abstract}
As características formais dos textos musicais são apenas um aspecto - um subconjunto, por assim dizer - de um sentido mais amplo do que é ser musical, o que inclui também o aspecto contextual e o cultural. Ao invés de ser concebida como se fosse basilar ou separável do contexto, a estrutura é tomada como tendo entre suas funções centrais a construção do contexto social. (Monson apud Cook, 2006, p. 11)
\end{abstract}

Seguindo esse raciocínio, percebe-se a inconsistência de tratar texto e contexto como elementos dicotômicos, separados (dentro e fora). Kevin Korsyn (2001, p. 55) argumenta que "Conceber texto e contexto como uma oposição estável leva a uma compartimentalização da pesquisa musical, separando a análise sincrônica da estrutura interna das narrativas diacrônicas da história", ${ }^{3}$ e

\footnotetext{
3 Tradução nossa do original: "Conceiving text and context as a stable opposition promotes a compartmentalization of musical research, dividing the synchronic analysis of internal structure from the diachronic narratives of history".
} 
adiante ilustra da seguinte maneira, "como se a peça fosse criada fora do tempo e caísse de paraquedas dentro da história". "Dessa forma, se apenas como especulação teórica insistirmos nessa separação, perceberemos que o texto em si apresentará já diversas características relativas ao seu contexto (termo aqui ainda empregado de forma ampla, isto é, elementos culturais, históricos, situacionais etc.). Citando Korsyn, "o contexto invade o texto". 5 O mesmo ocorrerá ao descrevermos apenas elementos contextuais: as próprias performances passarão a ser elementos constituintes dessa descrição.

Para ilustrar o dito acima, ao se considerar elementos estruturais de uma composição (notação) ou mesmo da própria realização musical, perceberemos que os parâmetros composicionais como harmonia, elementos rítmicos, estrutura formal etc., assim como o modo de se vestir do performer, a técnica utilizada, entre outras, por si já descrevem também elementos contextuais, como: o enunciatário pressuposto, valores socialmente considerados positivos musicalmente, valores estilísticos, decoro etc. Da mesma forma, ao descrevermos valores socioculturais do início do século XIX europeu, por exemplo, as próprias composições refletirão elementos valorados por essa sociedade em termos de estilo, disposição formal, instrumentação etc.

Reiterando que, além de refletirem elementos contextuais, as próprias obras (aqui nos referimos à partitura), enquanto objeto artístico, bem como suas realizações, são fruto e também formadoras desse contexto cultural. Nas palavras de Korsyn (2001, p. 58), "texto e contexto condicionam-se reciprocamente". ${ }^{6}$ Assim, ao assistirmos performances musicais em competições de instrumentistas solo nos dias de hoje, por exemplo, do mesmo modo, elas refletirão valores considerados eufóricos pela sociedade. Nesse caso, características como alta competência técnica, ausência de erros, andamentos acelerados, entre outras, são valores esperados para o virtuose de hoje em dia.

Os valores eleitos pela sociedade como essenciais e significativos, bem como suas funções, estão em constante movimento, não são fixos e estáveis. Dentro dessa dinâmica, o performer não precisa, necessariamente, almejar e compactuar com esses valores, podendo inclusive ir contra ou propor-lhes novas formas de valoração.

Por ora, a despeito de se considerarem o texto e o contexto como partes integrantes e inerentes ao nosso objeto, como propomos aqui, é importante sublinhar que cada vez mais a pesquisa em performance toma elementos contextuais como pertinentes ao estudo, o que reflete a busca em melhor delinear o objeto da performance musical, além de lhe propor mudança nas

\footnotetext{
${ }^{4}$ Tradução nossa do original: "As if the piece were created outside time and then parachuted into history".

${ }^{5}$ Tradução nossa do original: "Context invades text".

${ }^{6}$ Tradução nossa do original: "Text and context reciprocally condition each other".
} 
estratégias de investigação. Isso porque passa-se a considerar na performance não apenas os aspectos estritamente internos, ou seja, suas estruturas e relações propriamente musicais, mas passa-se a observar também outros valores que se investem na realização musical, que não apenas localizam a performance histórica e socialmente, atribuindo-Ihe valores, mas tornam a própria realização formadora do contexto sociocultural.

Se o contexto é incorporado à discussão, então voltamos a Schwartzmann (2018) e vemos esse contexto como uma coleção de textos em interação, como também na citação de Barros (2005). O que habitualmente chamamos de texto e contexto - dando uma proeminência para o texto e deixando indefinidos os participantes do contexto como um emaranhado de fatores - são, na verdade, uma série de textos coordenados em torno de um ato comum: a performance. Se temos uma composição de textos de diferentes ordens presentes na performance, surge a questão de sua interação. Somos então levados à discussão do sincretismo de linguagens.

\section{Sincretismo}

Numa performance, o intérprete não se vale apenas de escolhas estritamente musicais. Ao lado dos sons, ele possui diversas outras possibilidades de linguagens à sua disposição. Dessa forma, poderíamos falar de gestos corporais, expressões faciais, roupas, postura etc., elementos presentes numa performance e potencialmente carregados de sentidos. Como diz Berio, "um concerto também é um espetáculo. Uma performance de concerto, quer se goste ou não, é também um teatro em potencial" (Berio apud Bonin, 2019, p. 169). Dito de outra forma, numa performance musical estão em jogo outros elementos, para além dos sons musicais, que também compõem a completude de uma realização musical. Naturalmente, esses elementos podem ser construídos propositalmente ou à revelia do intérprete, mas mostram-se materialmente representados no enunciado musical.

Interessante notar que os elementos destacados acima não são novos numa realização musical; muito pelo contrário, sempre estiveram presentes e são condição sine qua non da performance. No entanto, seja por reprodução de ideologia calcada na hegemonia da notação ou pela pesquisa em performance dar ênfase, inicialmente, quase que exclusivamente ao parâmetro som-frequência, esses elementos foram simplesmente desconsiderados dos estudos musicais. Como aponta Bonin:

Se, por muito tempo, nas pesquisas e investigações sobre a linguagem musical, nos preocupávamos, principalmente, em fazer triagens que isolariam o objeto das demais manifestações, como no caso dos estudos que tomavam o som-frequência pura como o principal elemento de geração do sentido musical, para ficarmos 
num exemplo, talvez estejamos, neste momento, procurando observar nos objetos musicais os elementos que se misturam para formar o sentido geral de uma obra, tanto no que se refere às misturas no interior da linguagem musical, os contatos entre diversos sistemas e culturas musicais, quanto às interações com outras práticas e linguagens. (Bonin, 2019, p. 183)

Essa busca por considerar a performance musical em sua completude, levando em consideração outros elementos presentes no ato, além do somfrequência, vem se consolidando paulatinamente no meio acadêmico, como nos trabalhos de Jane Davidson (2002) sobre comunicação corporal na performance, de Bruno Madeira (2017) sobre gestos corporais, entre outros. Todavia, na medida em que se complexifica o objeto, novos desafios também aparecem. Além dos motivos citados anteriormente (hegemonia da notação e ênfase única no som-frequência), essa pode ser também uma das razões por se ter evitado tratar desses componentes inicialmente nas pesquisas. Em outras palavras, o pesquisador que buscasse investigar esses elementos, num primeiro momento, não encontraria trabalhos metódicos dentro da pesquisa em performance. Sendo assim, deveria debruçar-se em estudos de outras áreas do conhecimento, que possuem investigações sistemáticas sobre determinado elemento, para posteriormente aproximá-los das problemáticas da performance musical e avaliar a pertinência e exequibilidade nesse contato.

Interessante notar que, em especial na música experimental da segunda metade do século XX, muitos compositores apresentaram propostas que justamente procuravam explicitar elementos que já estavam presentes na construção musical em qualquer época. Tais elementos são, na verdade, centrais, mas foram, de certa forma, obscurecidos pelos elementos fixados pela notação tradicional (altura, ritmo etc.) (Lemos; Lemos, 2019, p. 183). Dessa forma, ao incluir descrições específicas nas composições sobre como se vestir, qual gesto deveria ser feito, movimentações específicas no palco, cenário, posicionamento etc., além de darem relevo a esses elementos e/ou the proporem novas formas de significação, colocam em xeque seu caráter acessório, isto é, revelam seu papel constituinte na performance musical e, consequentemente, parte do próprio objeto de estudo.

Para viabilizar o estudo da performance musical em sua completude, ou seja, pelo acionamento de várias linguagens de manifestação em sua enunciação/realização musical, é preciso tratar de dois aspectos: o primeiro é a definição de objeto sincrético (Greimas; Courtés, 2011, p. 467) e a discussão a respeito de questões de seu funcionamento; o segundo é a investigação de quais as linguagens em jogo na performance musical e a pertinência de cada uma.

Se constatamos uma variedade de textos sendo acionados na performance, como discutimos no item anterior, poderíamos supor que estaremos diante de múltiplas enunciações dispostas lado a lado. No entanto, se reconhecemos na 
performance um projeto comum, é preciso supor uma única força organizadora, uma única enunciação: estamos diante de um objeto sincrético. Como explica Lemos (2021), "O sincretismo é uma superposição, uma suspensão de diferenças. Isso se dá quando a diferença entre dois [ou mais] elementos do plano da expressão justapostos ou sobrepostos é suspensa e ambos os termos parecem transmitir um mesmo sentido". F Fiorin explica nos mesmos termos, mostrando a incoerência de tratar o ato sincrético como um conjunto de várias enunciações:

\begin{abstract}
Se houvesse uma enunciação para cada linguagem, o resultado seria colocar uma linguagem ao lado da outra, sem que houvesse uma superposição da forma de expressão e, por conseguinte, sem que dela resultasse um sincretismo. Ao contrário, temos uma única enunciação sincrética, realizada por um mesmo enunciador, que recorre a uma pluralidade de linguagens de manifestação para constituir um texto sincrético. Essa estratégia constitui uma estratégia global de comunicação, que se vale de diferentes substâncias para manifestar, na textualização, um conteúdo e uma forma de expressão. (Fiorin, 2009, p. 38)
\end{abstract}

Todavia, do ponto de vista metodológico, ainda que estejamos nos referindo à apreensão da enunciação sincrética de forma global, é preciso reconhecer que há diferentes manifestações em jogo, ou seja, "o que importa é mais o que une do que o que separa os elementos de manifestações distintas, precisamos ainda assim admitir que, para falar de junção, é preciso reconhecer uma distinção" (Lemos, 2021). Dessa forma, na análise de um texto sincrético, o estudioso precisa conhecer suficientemente as linguagens em jogo, ainda que conte com o mesmo ferramental teórico-metodológico para a abordagem das diversas manifestações. Ainda assim, "A utilização desse ferramental teórico único não exclui os estudos individuais das expressões, aliás depende deles" (Lemos, 2021).

Com isso, através de análises particulares das manifestações presentes no ato performático, considerando as ferramentas teóricas pertinentes que subsidiem a análise de cada manifestação, e tendo como laço teóricometodológico unificador a semiótica tensiva, chegaremos a determinadas cifras tensivas. Desse modo, teremos "a possibilidade de contrastar e homologar as análises da expressão em termos semelhantes" e, com isso, verificar "se a análise das expressões aponta para uma convergência ou para um conflito entre as diferentes linguagens" (Lemos, 2021). Sublinho mais uma vez que a área musical não deve prescindir de seus métodos de análise, pelo contrário, eles são necessários. Sobre isso, Lemos é enfática:

\footnotetext{
${ }^{7}$ Não nos referimos à paginação das passagens citadas pois o livro ainda se encontra no prelo.
} 
A proposta não é a de abandonar as análises específicas, a de substituir ferramentas analíticas por algumas poucas categorias totais. A análise em categorias tensivas no plano da expressão depende diretamente do estudo das formas específicas de cada linguagem - lembrando que as linguagens de manifestação que participam no sincretismo não perdem a sua forma em nome de uma forma total. (Lemos, 2021)

As análises individuais das linguagens de manifestação geram cifras tensivas ${ }^{8}$ que, individualmente, não refletem o sentido do objeto como um todo. Isso porque as manifestações podem seguir vetores em diferentes direções. Para ilustrar, numa realização musical, o elemento sonoro musical pode constituir-se de maneira a gerar efeito de grandiosidade, solenidade, por exemplo. Todavia, se por outro lado, o performer estiver com o olhar mirado na audiência fazendo caretas debochadas, o efeito de sentido será diverso daquela solenidade aferida pela análise do elemento sonoro musical. Assim, o sentido se dará nas relações entre as manifestações em jogo. No exemplo citado, provavelmente uma sátira, piada etc., a depender das outras manifestações em jogo, bem como pelas condições contextuais. Nesse sentido, Bonin diz:

\begin{abstract}
Se reconhecemos no objeto traços de mais de uma linguagem em contato, então há, entre as presenças, uma medida que tensiona e configura a percepção do objeto, a ponto de essa tensão modificar o modo como cada linguagem separada é constituída naquela manifestação notadamente sincrética. (Bonin, 2019, p. 167)
\end{abstract}

A partir do pequeno exemplo dado acima, percebe-se que essa apreensão de sentidos do objeto como um todo irá modificar a própria constituição das manifestações caso fossem pensadas de maneira individual, como aponta o autor. Fato que não contradiz o que foi dito sobre o analista possuir expertise de análise nas manifestações individuais, como vimos argumentando, aliás depende dela. É só a partir da análise individual e do contraste de suas convergências e divergências que se pode chegar a uma equação global da estrutura dos sentidos no sincretismo.

\title{
3.1. Sonoridade e teatralidade
}

Cabe agora levantar as linguagens de manifestação em jogo e como elas se relacionam para um sentido global do ato performático. Num primeiro momento, a resposta é fugidia, pois necessita cobrir uma quantidade inumerável de diferentes propostas que cabem dentro do termo performance musical. Vamos considerar, inicialmente, a performance musical de um solista de música

\footnotetext{
${ }^{8}$ Cifra tensiva é um termo da metalinguagem da semiótica tensiva. O termo sugere uma equação subjetiva entre o estado de alma e o estado de coisas, ou seja, de como o sujeito apreende os acontecimentos, mais ou menos impactantes, que entram no campo de presença.
} 
instrumental. Isso porque, como aponta Bonin, esse tipo de performance - e isso se aplica a outras formações também - "[goza] de estabilidade histórica e estrutural dentro da linguagem musical, o que constrói uma certa ideia de normalidade com relação à sua constituição" (2019, p. 170). Além disso, a estabilização de uma prática cria expectativas consolidadas pelo tempo que, apesar de não garantirem definitivamente a composição final de fatores, tende a uma maior constância do que formações mais recentes e experimentais.

$\mathrm{Na}$ apresentação de um instrumentista solo então, além dos elementos sonoros musicais, uma outra presença constante é a própria visualidade, considerando toda a amplitude do termo, disponível ao enunciatário. Elemento que poderíamos subdividir em diversas outras subcategorias, como: gestos corporais, expressões faciais, vestimentas, cenário etc. Por ora, a título de simplificar a exposição, vamos agrupar todos esses elementos no que Bonin chama de uma certa "visualidade", uma certa "teatralidade" ou presença cênica.

Considerando, grosso modo, esses dois blocos de manifestação - isto é, os elementos sonoros musicais (também sons do ambiente, público etc.) e os demais elementos visuais em jogo - presentes numa performance instrumental solística, resta saber se essas grandezas gozam de mesmo estatuto, se as quantidades de presença são equivalentes e se uma rege a outra ou se se implicam mutuamente na mesma proporção. Bonin nos indica um caminho para os questionamentos acima ao investigar a música cênica:

\footnotetext{
Existe, portanto, uma dependência entre as quantidades de presenças - musical e cênica - que o sujeito estabelece para o objeto que se forma em seu espaço tensivo, e uma regência musical que atua como uma força que mantém, para o sujeito, uma base sensivel que se relaciona diretamente com a música enquanto linguagem matriz. (Bonin, 2019, p. 168)
}

O autor, ao buscar recursos que descrevam a Música Cênica, explana sobre as quantidades de presença (musical e cênica) no objeto. Para Bonin, essas presenças apresentam-se sempre em relação inversa, quanto mais de uma menos da outra. Além disso, ele considera a linguagem musical enquanto matriz a partir da qual as outras se mobilizam. Considerando o caso da performance musical instrumental solista, podemos pensar na presença cênica enquanto latência inerente à própria performance, como Gilberto Mendes descreve:

Parece que o teatro-musical vem daí, né? Daquilo do teatro que a gente faz, né? Razão porque a gente é ator também, é intérprete. A gente pisa muito no palco, a gente tem desembaraço, né? Mexe pra cá, vira pra lá, sobretudo o cantor. Está atuando, né? E a coisa dele [da música cênica] parece que surgiu da observação do que há de teatro também na interpretação musical... O pianista que entra, pega o piano, senta, não tá muito bom, levanta, acerta melhor; põe 
a partitura, ela cai no chão, ele pega... é um teatro isso aí. (Mendes apud Bonin, 2019, p. 169)

Todavia, em nosso caso, onde a presença cênica se refere substancialmente à gestualidade do performer, nem sempre a relação precisa ser inversa. Um amplo movimento gestual do performer concomitante à execução de um acorde em fortíssimo não diminui a presença musical; ao contrário, pode reforçá-la. Da mesma maneira, no caso de uma sequência de notas sendo tocadas em decrescendo até se tornarem inaudiveis, uma estratégia do performer pode ser utilizar apenas gestos (sem efetivamente tocar o instrumento), sugerindo o toque em pianíssimo das notas que antecedem o silêncio. Nesse exemplo, o gesto estaria enfatizando a presença musical.

Podemos argumentar por considerar a linguagem musical como matriz do ato performático, o que parece fazer sentido nesse contexto. Isso se justifica pois, ao separarmos os elementos sonoros musicais das outras manifestações, por exemplo, ainda assim podemos ter um objeto que forme um todo de sentido, como é o caso de gravações de áudio. O inverso não se sustentaria, isto é, retirar o áudio de uma realização musical, restando apenas os elementos visuais, e tratálo enquanto um objeto autônomo. Por outro lado, reconhecem-se performances musicais em que o aspecto sonoro está no limiar. E, assim, mesmo esse critério pode encontrar seus limites.

Ainda assim, quantificar essas manifestações e investigar os seus modos de contato é pertinente para descrever as características do objeto de estudo. Como aponta Lemos (2021), "É preciso supor que há uma interação particular entre as formas da expressão que leva a uma certa linguagem sincrética e não a outra. Isso porque a junção do verbal com o visual nem sempre leva à mesma linguagem". Da mesma forma, a junção entre música e visual pode configurar linguagens diversas como ópera, teatro musical, música cênica, até mesmo videoclipes e cinema etc. Assim, a autora pondera que isso "nos leva a pensar que o sincretismo não deva ser uma ferramenta de classificação de linguagens", mas tão somente uma ferramenta para sua descrição.

\section{Contribuições semióticas para a delimitação do objeto}

Nesse momento da discussão, percebe-se o grande número de fatores implicados na construção de sentidos numa performance musical, bem como a complexidade de considerá-los em toda a sua amplitude. Isso porque, de um lado, existe um grande número de variáveis ao buscar um olhar integrador sobre performance musical e, de outro, é preciso respeitar a própria natureza movente do objeto. 


\subsection{Os limites do texto}

Diante de cenário tão amplo, com múltiplas possibilidades de abordagens, Greimas nos ajuda a dar os primeiros passos, do ponto de vista metodológico, ao colocar o problema da semiótica discursiva frente à crescente complexificação dos objetos estudados.

[...] tudo nos predispõe a colocar o problema da semiótica discursiva em termos de estratégia e de tática: uma estratégia de conjunto para uma dada disciplina, segundo a qual os objetos semióticos simples devem ser examinados antes dos objetos complexos; uma tática particular, para a abordagem de cada objeto discursivo, que consiste em adotar o nível ótimo de análise, o melhor apropriado ao objeto, permitindo deliberar, ao mesmo tempo sobre a especificidade de um texto e sobre os modos de sua participação no universo socioletal. (Greimas apud Schwartzmann, 2018, p. 3)

Esse percurso proposto por Greimas, em termos de estratégia e tática, frente à crescente complexificação dos objetos investigados aponta caminhos para que o analista, dentro das especificidades do objeto, busque o que o autor chama de "nível ótimo de análise". Schwartzmann sugere que, "para Greimas, o texto era o nível de pertinência, ou, [...] o nível ótimo de análise, em que se podiam ver as estruturas significantes manifestadas" (Schwartzmann, 2018, p. 3). Todavia, como vimos argumentando, alguns dos aspectos que elencamos como pertinentes na construção dos sentidos de uma performance musical não se apresentam materialmente representados no texto enunciado, sendo necessário relacioná-lo ao seu entorno sociocultural, seus usos e a práxis em que se insere.

Dentro dessa perspectiva, Luiz Tatit, em seu livro Musicando a semiótica (1998), já apontava que os pesquisadores do discurso e do texto oscilavam entre dois enfoques interdependentes em suas investigações. Por um lado, incluindo na investigação elementos circundantes ao enunciado, algumas vezes perdendo o enfoque linguístico. Por outro, concentrando-se exclusivamente nos elementos que garantiriam a coerência do discurso, em muitos casos caminhando para uma gramaticalização do texto, isto é, uma análise apenas dos aspectos internos do enunciado.

De um lado, os lingüistas buscam elementos para a abordagem dos fenômenos da interdiscursividade, intertextualidade, heterogeneidade discursiva ou, ainda, de polifonia. De outro, não podem deixar de preocupar-se também com os fatores de coesão e de coerência discursiva e textual. No primeiro caso, a adoção progressiva de uma interdisciplinaridade - que vai da sociologia à psicanálise, passando por domínios da filosofia e da inteligência artificial - acaba, por vezes, conduzindo a pesquisa para fora da órbita propriamente lingüística, de modo que o texto torna-se apenas pretexto para uma verdadeira compulsão interpretativa. No segundo caso, a concentração excessiva sobre os fenômenos que garantem a coerência do discurso [...] muitas vezes caminha para 
uma gramaticalização do texto, com regras de reconhecimento e aceitabilidade completamente inadequadas a essa dimensão da análise. (Tatit, 1998, p. 75)

Tatit já apontava os ganhos operacionais da semiótica no sentido de criar condições teóricas para abordar fenômenos polifônicos e interdiscursivos, todos considerados fenômenos de enunciação. Entretanto, considerando o bordão do autor lituano, que ficou clássico na área semiótica, "Fora do texto não há salvação" (Greimas, 1974, p. 10), é preciso encontrar, para a abordagem de objetos complexos, como é o caso da performance musical, justamente uma forma de se desprender dos limites excessivamente rígidos do texto, sem, contudo, deixar a órbita do projeto linguístico, como advertia Tatit. Nas palavras de Schwartzmann:

A novidade está no que chamamos de "saída do texto", isto é, na ultrapassagem do nível do texto-enunciado, nível historicamente eleito por excelência, e no redirecionamento das análises e pesquisas na direção dos objetos semióticos, de sua relação com os sujeitos, ou ainda, com os corpos dos sujeitos e com práticas e usos sociais. (Schwartzmann, 2018, p. 4)

Conforme o autor explica, essa "saída do texto" não se contradiz com a teoria semiótica, já que uma leitura possível dentro da teoria é a de que, como já apontamos acima, "não há nada que, para a semiótica, não seja texto. Tudo é texto. Não se pode levar a cabo uma análise sem que se tome uma dada grandeza semiótica como um texto" (Schwartzmann, 2018, p. 2). Dessa forma, podemos considerar toda manifestação como texto ou propor uma semiotização da própria comunicação, dinâmica social, situações etc.

Assim, as palavras de Greimas parecem mais advertir o estudioso a não seguir caminho calcado em impressões subjetivas e/ou perspectivas psicologizantes, que invalidariam os esforços da semiótica para se constituir cientificamente, do que impor os limites descritivos do objeto. Isso significa que, no caso da realização musical, a depender da complexidade do objeto e do interesse que subjaz à análise, caberá ao analista identificar e, a partir de levantamento e investigação dos elementos envolvidos na produção dos efeitos de sentido no ato performático, traçar os níveis de pertinência de seus constituintes, ainda que rastros enunciativos não se encontrem no texto enunciado e, no entanto, como argumentaremos aqui, relacionem-se com o ato de maneiras menos explícitas, como por coerções sociais ou por demandas de uma determinada práxis. Sobre isso, Greimas e Courtés explicam que:

Nem o texto é, portanto, um limite, uma baliza, sendo antes um limiar que pode ou não ser ultrapassado, a depender das escolhas ou interesses do analista, nem a análise semiótica se reduz à sua própria metodologia, na medida em que o que a define são os 
procedimentos de descrição, regidos sempre pela simplicidade, pela exaustividade e pela não contraditoriedade. (Greimas; Courtés, 2008, p. 194)

A citação prevê a dinâmica adaptativa que a teoria semiótica viria a enfrentar frente a novas problemáticas e à crescente complexificação dos objetos. Ainda que se admita a movência necessária ao amadurecimento teóricometodológico, os autores não abrem mão de princípios que garantam uma abordagem científica: a descrição simples, exaustiva e não contraditória (Hjelmslev, 2003, p. 11).

\subsection{A performance musical entre enunciador e enunciatário}

Como discutido até aqui, a performance musical constrói-se como um objeto complexo e dinâmico cuja rede de relações dialógicas influem em seus sentidos. A partir disso, mostra-se improdutivo almejar definir rigidamente seus limites descritivos bem como propor caminho fixo para sua abordagem, já que a própria constituição do objeto pode variar grandemente. Todavia, apesar de buscar abarcar a natureza dinâmica, o método de investigação não deve se confundir com uma abordagem aleatória feita caso a caso, mas deve entender as condições de realização e as relações que se constroem. Como explica Fiorin sobre a movência ou instabilidade de valores no discurso:

\footnotetext{
Instável é o que não é fixo, o que não é permanente e, sobretudo, o que muda de lugar. O discurso mostra que certas formas que o sistema apresenta como absolutamente estáveis mudam, dadas certas condições (de ordem discursiva, é evidente), de lugar, adquirem novos valores, geram novos significados, enfim engendram o que os que trabalham com discurso aprenderam a chamar efeitos de sentido. Essa instabilidade, para seguir o princípio da teoria do caos, não é aleatória, mas resultante de certos fenômenos. O estudo da instabilidade exige que se estabeleçam suas condições de realização e as matrizes semânticas dos efeitos de sentido que, num processo de concretização crescente, vão manifestar-se em cada texto. (Fiorin, 2016, p. 18)
}

Em outro trabalho (Lemos, 2019), levamos em consideração elementos específicos das performances analisadas: música/áudio, gesto corporal e expressão facial, vestimenta, instrumento e escolhas de câmera (haja vista que se tratava de performances capturadas em vídeo). A movência, como vimos falando, faz com que a definição de seus componentes por meio de uma lista seja pouco produtiva. Isso porque, em nova análise, poderíamos elencar outros fatores que se apresentassem pertinentes, assim como prescindir de alguns componentes citados acima. Elementos podem estar mais ou menos salientes: um cenário pode ser completamente neutralizado por escolhas da gravação, por exemplo. 
Assim, entre os limites do excessivamente restrito ao texto (no nosso caso, o musical) e excessivamente aberto a todas as relações intertextuais e interdiscursivas que se apresentam à análise, como colocado por Tatit, Barros sugere uma articulação por meio da instância enunciativa:

\begin{abstract}
Reconstrói-se a enunciação, por conseguinte, de duas perspectivas distintas e complementares: de dentro para fora, a partir da análise interna das muitas pistas espalhadas no texto; de fora para dentro, por meio das relações contextuais - intertextuais do texto em exame. A enunciação assume claramente, na segunda perspectiva, o papel de instância mediadora entre o discurso e o contexto sóciohistórico. (Barros, 2005, p. 78)
\end{abstract}

Assim, é preciso ter em mente que assistimos a performances musicais e o que parece estar realmente em jogo é esse contrato enunciativo: um espectador busca uma experiência musical proporcionada por outro sujeito; esse segundo sujeito oferece ao primeiro uma performance musical. Se o ato performático é de fato um sincretismo, uma composição de variadas manifestações, há um centro dêitico que organiza todos os demais valores: esse centro em torno do qual giram todos os elementos da performance é a relação pressuposta de alguém que enuncia e alguém que acolhe a enunciação. Entre enunciador e enunciatário, a performance.

O eixo enunciador-enunciatário oferece assim a referência de escolha, a cada caso, dos elementos pertinentes para a análise da performance. O pesquisador deverá se perguntar, a cada vez, quais os fatores que estão influenciando a apreensão do ato performático. Longe da indefinição aberta, essa tomada de partido pela enunciação nos oferece um parâmetro de escolha constante, que torna por isso mesmo comparáveis as performances mais variadas. Também aí não perdemos a centralidade da música, uma vez que ela está na raiz do contrato que se estabelece entre enunciador e enunciatário.

\title{
4.3. De volta ao contexto
}

Como foi levantado na discussão acerca da noção de contexto e de intertextualidade, a abrangência dos estudos sobre performance para além da materialidade do som pede a inclusão de considerações "extra-textuais" que vão desde os gestos, o ambiente, a expectativa do público, até as obras e performances com as quais se estabelecem diálogos, os códigos estilísticos de dada época, enfim, o social, a sociedade, a história. Entre essa enormidade inapreensível e o excesso restritivo da performance, foi preciso encontrar um objeto que fizesse jus ao que se pode chamar de ato performático.

Em vez de lançarmos mão de listas e tipologias de atos, buscamos o elemento constitutivo de uma performance, que são os atores desse evento. Sem o enunciador e o enunciatário, a performance se desfaz. Ao tomar esse eixo 
dêitico pressuposto como articulador dos elementos essenciais, dos valores relevantes da performance, podemos separar o principal do acessório, o interno do externo, e, assim, dar conta das movências do objeto sem perder, a cada caso, o que lhe é constitutivo. Esse movimento também redefine o que será intertextual, ou seja, tudo aquilo com que a performance dialoga, mas que não é parte inerente do ato.

\section{Conclusão}

Ao passar da intertextualidade ao contexto, do texto ao sincretismo e chegando às relações enunciativas em torno das quais se organizam os elementos da performance, buscamos traçar as condições de análise e apontar as relações que se estabelecem, mais ou menos explicitamente, para a construção de sentidos na performance musical. Assim, é possível apontar algumas diretrizes semióticas à pesquisa em performance.

Para além dos sons musicais e do apoio central da partitura, na realização musical o performer lida com elementos que escapam à prescrição notacional, além de ter à disposição outras linguagens de manifestação, como gestos, expressões faciais, vestimentas etc., também constituintes do ato performático como um todo, e que podem configurar escolhas deliberadas ou não do performer. No entanto, apresentam-se materialmente representadas no enunciado musical e também são importantes para a construção de sentidos. Sendo assim, classificamos o ato performático enquanto um objeto sincrético e fizemos considerações a respeito das possibilidades para sua investigação bem como de suas especificidades.

A performance musical, considerada em toda a sua completude, não deve ser direcionada, do ponto de vista analítico, exclusivamente pela constituição estrutural e pelas relações internas de seu componente estritamente sonoromusical, ainda que possuam grande relevância e centralidade. Deve sim ser pautada profundamente pelos diálogos que se estabelecem com outros enunciados, assim como com instâncias de mais difícil apreensão, como sociedade, cultura, costumes, decoro etc. Além do mais, essas relações podem estabelecer-se em diversos níveis, de maior ou menor impacto, assim como os efeitos de sentido oriundos dessa relação/tensão podem se configurar das mais diversas maneiras.

Ao movimento de abertura para o intertextual e o contextual, segue-se a necessidade da delimitação. A movência típica do ato performático - aliás, não apenas o musical - torna todo recorte descritivo de difícil determinação. Elementos mais pertinentes num caso podem se mostrar infrutíferos em outros, sobretudo se queremos abarcar performances mais contemporâneas e experimentais. O fator constante, como argumentamos, é a enunciação. O eixo 
enunciador-enunciatário distribui valores, estabelece importâncias e, assim, recorta limites: os limites constantes na relação enunciativa, os limites adequados a cada caso.

\section{Referências}

BARROS, Diana Luz Pessoa de. Teoria semiótica do texto. São Paulo: Ática, 2005.

BONIN, Gustavo. Modos de contato na música cênica contemporânea. Estudos Semióticos, v. 15, p. 167-183, 2019. DOI: 10.11606/issn.1980-4016.esse.2019.153770. Disponível em: https://www.revistas.usp.br/esse/article/view/153770. Acesso em: 31 mai. 2021.

COOK, Nicholas. Entre o processo e o produto: música e/enquanto performance. Per musi: revista de performance musical, (14), 5-22, 2006. Trad. Fausto Bórem, Belo Horizonte. Disponível em: http://www.musica.ufmg.br/permusi/port/numeros/14/num14_cap_01.pdf . Acesso em: 31 mai. 2021.

DAHLET, Patrick. Dialogização enunciativa e paisagens do sujeito. In. BRAIT, Beth (org.). Bakhtin: dialogismo e construção do sentido, p. 55-84. Campinas: Ed. Unicamp, 2005.

DAVIDSON, Jane. Communicating with the body in performance. In: RINK, John (org.). Musical performance: a guide to understanding. Cambridge: Cambridge University Press, 2002, p. 144152.

DISCINI, Norma. Intertextualidade e conto maravilhoso. 2. ed. São Paulo: Humanitas, 2004. FIORIN, José Luiz. Para uma definição das linguagens sincréticas. In. OLIVEIRA, Ana Cláudia Mei de; TEIXEIRA, Lucia (org.). Linguagens na comunicação: desenvolvimentos de semiótica sincrética, p. 15-40. São Paulo: Estação das Letras, 2009.

FIORIN, José Luiz. As astúcias da enunciação: as categorias de pessoa, espaço e tempo. 3. ed. São Paulo: Contexto, 2016.

FONTANILLE, Jacques. Práxis e enunciação: Greimas herdeiro de Saussure. Gragoatá, Niterói, v. 22, n. 44, set.-dez. 2017, p. 986-1004.

FOUCAULT, Michel. Estética: literatura e pintura, música e cinema. 3. ed. Trad. Inês Autran Dourado Barbosa. Rio de Janeiro: Forense, 2013.

GREIMAS, Algirdas Julien. A enunciação: uma postura epistemológica. Trad. Maria Lúcia Vissotto Paiva Diniz. Significação: revista brasileira de semiótica, (1), p. 9-25, 1974.

GREIMAS, Algirdas Julien; COURTÉS, Joseph. Dicionário de semiótica. 2. ed. Trad. Alceu Lima et al. São Paulo: Contexto, 2011.

HJELMSLEV, Louis. Prolegômenos a uma teoria da linguagem. São Paulo: Perspectiva, 2003 KORSYN, Kevin. Beyond privileged contexts: intertextuality, influence, and dialogue. In. COOK, Nicholas; EVERIST, Mark. Rethinking music.. Oxford: Oxford Univerty Press, 2001, p. 55-72.

LEMOS, Caio Victor de Oliveira. Performance musical como discurso: proposta de análise. Vórtex, v. 7, n. 1, 2019, p. 1-31. Disponível em: http://vortex.unespar.edu.br/lemos_v7_n1.pdf. Acesso em: 31 mai. 2021.

LEMOS, Caio Victor de Oliveira. Atores e funções na realização musical. Anais do XXVIII Congresso da ANPPOM, v. 28. Manaus: ANPPOM, 2018. Disponível em: https://anppom.org.br/anais/anaiscongresso_anppom_2018/5439/public/5439-18132-1PB.pdf. Acesso em: 27 jul. 2021. 
LEMOS, Caio Victor de Oliveira; LEMOS; Carolina Lindenberg. Discussões epistemológicas acerca da noção de identidade na obra musical. In. Anais da Performus'19, Goiânia, 2019.

LEMOS, Carolina Lindenberg. A transversalidade das categorias tensivas no tratamento da Expressão. In. SCHWATZMANN, Matheus Nogueira; PORTELA, Jean Cristtus; DONDERO, Maria Giulia (org.). Linguagens sincréticas. novos objetos, novas abordagens teóricas. Campinas: Pontes Editores, 2021 (no prelo).

MADEIRA, Bruno. O gesto corporal como potencializador de significado na performance violonística. Tese (Doutorado em Música) - Universidade Estadual de Campinas, Campinas, SP, 2017.

NAVICKAITĖ-MARTINELLI, Lina. P is for persona, performance, pogorelich: the performer's identity as creative tool. Music \& practice, v. 5, 2019. Disponível em: https://www.musicandpractice.org/wp-content/uploads/2019/12/LNM-PDF-1.pdf. Acesso em 31 de mai. 2021.

SCHWARTZMANN, Matheus Nogueira. A noção de texto e os níveis de pertinência da análise semiótica. Estudos Semióticos [online], v. 14, n. 1 (edição especial). São Paulo, mar. de 2018, p. 1-6. DOI: https://doi.org/10.11606/issn.1980-4016.esse.2018.144288. Disponível em: https://www.revistas.usp.br/esse/article/view/144288. Acesso em: 8 dez. 2021.

TATIT, Luiz. Musicando a semiótica: ensaios. São Paulo: Annablume, 1998. 


\section{do Music performance as a research object}

\section{(D) LEMOS, Caio Victor de Oliveira}

Abstract: The objective of this article is to identify the construction of common directionalities between the concepts of border and threshold within the semiotic theory of culture through Yuri Lotman and Claude Zilberberg. To address our research objective, we conducted a critical, convergent and synthetic review of the representative literature of both authors' proposals. This methodological purpose aims to make an integrated reading of the concepts of border and threshold so that they generate new frameworks and thematic perspectives on a semiotics of culture. The hypothesis is that the articulation of the threshold within the theory of a culture dependent on the topological, fundamental and narrative opposition between the center and the periphery, allows the portrayal of more versatile semiospheres where the peripheral figure falls apart in the most ubiquitous and temporarily unstable movements of particular cultures such as those economic or consumer semiospheres.

Keywords: musical performance; syncretism; intertextuality.

\section{Como citar este artigo}

LEMOS, Caio Victor de Oliveira. Performance musical enquanto objeto de pesquisa. Estudos Semióticos [online], volume 17, número 3. Dossiê temático: "Semiótica, Música e Canção". São Paulo, dezembro de 2021, p. 326-346. Disponível em: www.revistas.usp.br/esse. Acesso em: $\mathrm{dia} / \mathrm{mês} / \mathrm{ano}$

\section{How to cite this paper}

LEMOS, Caio Victor de Oliveira. Performance musical enquanto objeto de pesquisa. Estudos Semióticos [online], vol. 17.3.Thematic issue: "Semiotics, Music, and Song". São Paulo, december 2021,p. 326-346. Retrieved from: www.revistas.usp.br/esse. Accessed: month/day/year.

Data de recebimento do artigo: 31/05/2021.

Data de aprovação do artigo: 27/07/2021. 